\title{
LA PRÁCTICA BENÉFICA Y EL CONTROL DE LOS SECTORES POPULARES DE LA CIUDAD DE BUENOS AIRES, 1890-1910
}

\author{
POR \\ EDUARDO O. CIAFARDO \\ Universidad Nacional La Plata
}

Al abandonar el siglo XIX, los habitantes de Buenos Aires ven esfumarse su vida, relativamente apacible, de tradición colonial. Entre 1880 y 1900, la ciudad cambia rapidamente su fisonomía urbana y sus costumbres, muchas de las cuales arrastraba desde los tiempos de la colonia. A comienzos del siglo Xx la ciudad se reconoce a sí misma en una moderna Babel. Los cronistas resaltan el bullicio y el movimiento de la gente; el crecimiento apresurado y desprolijo del tejido urbano mas allá del centro y las reformas urbanas hechas en el mismo, que no hacían más que mostrar a quien quisiera verlo, el orgulloso ingreso en la modernidad de una ciudad de pronto llamada a ser importante. En fin, 1910, el año de los grandes festejos del Centenario de la Revolución de Mayo, descubre una Buenos Aires que, para satisfacción de los sectores dominantes porteños, muchos viajeros encontraban parecida a importantes urbes europeas (1).

La ciudad patricia, en la que los pobres podían llegar a ser vistos solamente cuando se iba a su encuentro, y en la que las clases populares estaban confinadas en barrios apartados que constituían "un mundo aparte del centro de la ciudad» (2) cambia sustancialmente en pocos años. Para sorpresa de la élite porteña, en los primeros años del siglo no hacía falta que la curiosidad excitase a nadie para que, adrede, buscara el triste espectáculo de

(1) Un excelente estudio de contrastes de la ciudad de Buenos Aires entre 1870 y 1910, puede encontrarse en James ScobIE, Buenos Aires. Del centro a los barrios (1870-1910), Buenos Aires, SolarHachette, 1977

(2) José Luis, Romero, Latinoamérica. Las ciudades y las ideas, México, siglo XXI, 1976, pág. 237. 
la pobreza. Sin necesidad de ir a su encuentro, «el tétrico cortejo de la miseria» iba hacia ellos y, para contemplarlo, no se necesitaba sino esperar la hora propicia, «la hora negra, en la cual, los vencidos de la vida, extenuados por la lucha, sin casa y sin abrigo, se dejan caer allí donde los ha agarrado el agotamiento de fuerzas o la desesperación de conquistarse por el momento un pedazo de pan. Es doloroso y tan infinitamente triste como un campo de batalla después de la embriaguez épica del combate, el cuadro que ofrece esta gran ciudad en las primeras horas de la madrugada" (3).

Inmerso en ese clima de transformación, el viejo patriciado urbano de Buenos Aires repentinamente descubre antes que nadie, alrededor de 1880, que su ciudad "la Gran Aldea», comenzaba a transformarse en un conglomerado heterogéneo y confuso, en el que se uperdían poco a poco las posibilidades de control de la sociedad sobre cada uno de sus miembros, a medida que desaparecía la antigua relación directa de unos con otros» (4). El cambio era profundo y evidente y por lo tanto el «Orden» acuñado en el período Rosista no era ya efectivo ni posible en un recinto urbano definitivamente transformado. En el trayecto que va desde la "Gran Aldea" a la "Paris de Sudamérica», los sectores dominantes de Buenos Aires, dotaron a su ciudad de una estructura institucional que hizo posible la creación y la posterior conservación del orden social imprescindible para el crecimiento del nuevo país.

En esa época, se verifica, también, el inicio de un proceso sobre el que pretendemos hacer algunas consideraciones en el presente artículo: el paso de un sistema de caridad y beneficencia (5), que puede conceptualizarse como antiguo, sustanciado en las acciones individuales de la limosna o en una ayuda pública más o menos indiscriminada, a otro sistema catalogado como más racional y más útil, y por oposición como moderno, apoyado en una acción colectiva y con explícitos fines sociales (6). En este contexto, la ciudad de Buenos Aires comienza a verse literalmente

(3) Las Conferencias de Señoras de San Vicente de Paul de la República Argentina, 1889-1914, Buenos Aires, Cía. Sudamericana de Billetes de Banco, 1915 , pág. 6.

(4) ROMERo [2], pág. 270.

(5) Si bien existen diferencias formales en cuanto a su significado a lo largo del trabajo los términos "caridad", "beneficencia" y "filantropía", serán usados indistintamente.

(6) Ricardo, González, "Caridad y filantropía en la ciudad de Buenos Aires durante la segunda mitad del siglo XIX». En Diego ArmuS, (comp.). Sectores populares y vida urbana, Buenos Aires, CLACSO, 1982. 
invadida por instituciones caritativas y benéficas: decenas de asilos para niños y para mujeres jóvenes; algunos otros, los menos, para menesterosos y ancianos indigentes; asociaciones de enfermos pobres; movimientos antialcohólicos, antisifilíticos; ligas de madres y padres de familia, comedores gratuitos para mujeres embarazadas y/o con lactantes, casas cunas y "copas de lechen; refectorios para obreros, escuelas de artes y oficios, patronatos, orfanatos. Todas son sociedades que responden claramente a la nueva caracterización de la caridad y la beneficencia: desarrollando vastos programas de acción social, de vigilancia y control, dejando de lado la costumbre de una limosna que se repartía desprolijamente, en general los domingos a la salida de los servicios religiosos o en algunas situaciones extraordinarias.

\section{HACIA UNA «NUEVA ECONOMÍA DE PODER»}

Poco a poco, la ciudad sarmientina del Facundo que encerraba en ella todo lo que la civilización y el progreso podían ofrecer, será destruida por la prédica de los intelectuales ligados al positivismo. Ya a principios de siglo la ciudad deja de ser lo pulcro y se convierte en lo hediondo, lo sucio; deja de ser la luz para convertirse en sinónimo de oscuridad; la ciudad no es ya lo opuesto a la montonera salvaje, sino el caldo de cultivo de enfermedades, locos y delincuentes. Asociado al auge del positivismo, la miseria y el pauperismo tienden a perder definitivamente cualquier valor estético (bueno o malo) y van a pasar a ser identificados como el caldo de cultivo ideal del vicio y el crimen. Junto al discurso criminológico de los positivistas aparece, también en un lugar hegemónico, el de los médicos higienistas, que asociando sistemáticamente la miseria con la enfermedad, alertaban a los sectores dominantes acerca de las precarias condiciones materiales de vida de los pobres urbanos. De la mano del higienismo la vivienda de los pobres, el hogar de las capas inferiores de los sectores populares, se convierte en una de las preocupaciones preferentes de los sectores dominantes porteños.

La necesidad de acceder por algún medio a la intimidad de los sectores populares, determina el cambio en las formas de asistencia a los mismos. La reorientación de la práctica benéfica fechada en los años que marcan el cambio de siglo, es en parte producto también, de la intensa labor desarrollada por algunos intelectuales: principalmente médicos, pero no pocos abogados y 
criminólogos, que no se cansan de advertir a los sectores dominantes urbanos acerca de los trastornos que podrían sucederse en el futuro si no se tomaban urgentes medidas para integrar a los "pobres" de Buenos Aires en espacios de socialización institucional. Muchos de estos intelectuales, creen que las sociedades de beneficencia son una herramienta ideal para acceder a ellos y lograr esa integración (7).

Por este motivo intentan trazarles las líneas políticas básicas que deben desarrollar para convertirse en un elemento pausible de ser utilizado en la creación y mantenimiento de un cierto orden social. La explosión benéfica finisecular, no puede explicarse, pues, como la reacción de espíritus sensibles ante la injusticia social, sino como una acción política racional, compleja y consciente, en la búsqueda de crear y luego mantener el orden social necesario para el funcionamiento de un "nuevo" país. En consecuencia, analizar el papel de las instituciones de beneficencia desde un punto de vista tradicional lleva, inevitablemente, a perder de vista sus, tal vez menos evidentes pero seguro más importantes, objetivos de control social. Las prácticas benéficas y las sociedades caritativas que las generan, que inundan al Buenos Aires finisecular, son parte integrante de un dispositivo disciplinario general que debe permitir expandir y articular mecanismos de control social en una unueva» ciudad (8).

En términos de Michel Foucault, la ciudad de Buenos Aires asiste en esos años a la formación y consolidación de una nueva "economía de poder» que tendrá como característica excluyente, permitir que los efectos de poder circulen de forma continua e ininterrumpida en la sociedad. Esta nueva "economía de poder» posee técnicas que son mucho más eficaces que las utilizadas

(7) Cfr. por ejemplo Ricardo DEL CAMPO, Régimen de Beneficencia. Bases para su reforma Buenos Aires, Peuser, 1895 (Tesis): Luis CAMPos Urouiza. La bene/icencia, Buenos Aires, Cia Sudamericana de Billetes de Banco, 1897; Alberto Meyer Arana, Apuntes sobre beneficencia, Buenos Aires, 1898, (Tesis); Samuel GACHE, "El pauperismo y la caridad en Buenos Aires. Necesidad de organizar convenientemente la caridad". En Revista de Derecho, Historia y Letras. Tomo 6, págs. 518 y ss., 1900; Alberto LóPEz, La Asistencia Pública, Buses para su organización. Buenos Aires, 1912 (Tesis) y Julian Alderete, La Asistencia Pública, Bases para su organización, Buenos Aires, 1911 (Tesis).

(8) Entendemos por dispositivo un conjunto "resueltamente heterogéneo, que implica discursos, instituciones, disposiciones arquitectónicas, decisiones reglamentarias, leyes, medidas administrativas, enunciados científicos; proposiciones morales, filosóficas, filantrópicas; (...) el dispositivo mismo es la red que puede establecerse entre esos elementos". El "dispositivo", además, es una formación que "en un momento histórico dado, ha tenido como función principal la de responder a una urgencia". Michel Foucaul., "El juego de Michel Foucault". En: El discurso del poder. México, Folios, 1983, págs. 185-186 
anteriormente, ya que son menos susceptibles de escapatorias o de generar resistencias y menos costosas económicamente (9). Así, la tarea desarrollada por las sociedades de beneficencia será trascendente, ya que en una sociedad de clases en formación, como la argentina de los años tratados, el surgimiento y posterior institucionalización de un sistema racional de beneficencia va a representar un importante laboratorio de ideas y de iniciativas prácticas, de donde posteriormente saldrán técnicas y estrategias de sometimiento y control de masas que se tornarán indispensables para el dominio de clase de los sectores dominantes (10). La organización de un moderno modelo de beneficencia, se vincula, entonces, a la necesidad de construir un sistema asistencial que fuese capaz de adaptarse armoniosamente a sus nuevas funciones de control dentro una sociedad que descubría problemas sociales en torno a las condiciones de vida de los "pobres». En nuestra opinión, las asociaciones de beneficencia no desempeñaron durante el período analizado un rol simplemente asistencial, pretendiendo aliviar las miserias sociales desencadenadas por el desarrollo de una incipiente economía de tipo capitalista no regulada, sino que van a ser, fundamentalmente, «organizaciones de disciplinamienton, con objetivos religiosos (conversión al catolicismo y moralización cristiana), económicos (incitación al trabajo) y políticos (lucha contra la agitación anarquista o socialista). En su desarrollo institucional, la beneficencia se convertirá en un aparato de control económicamente ventajoso (en la medida en que posibilita el disciplinamiento y capacitación laboral de parte de la población) y políticamente útil (en la medida en que permite oponer prácticas sociales en un terreno que estaba potencialmente dominado por la actividad política de grupos anarquistas y socialistas radicalizados) (11).

En gran parte de los estudios historiográficos que abarcan temáticamente la llamada "cuestión social» de principios de siglo, tiende a prestársele demasiada atención a estas manifestaciones de poder básicamente represivas y que, en última instancia, por las características dispersas de su acción concreta, afectan indiscriminadamente a un amplio sector social contenido en la cate-

(9) Michel, Foucaul.T, "Verdad y poder". En: Microfisica del poder, Madrid, La Piqueta, 1984, pág. 183. 140.

(10) Robert CASTEl, El orden psiquiátrico. Madrid, La Piqueta, 1983, pág.

(11) Para un desarrollo amplio de estos puntos, ver: Eduardo Ciafardo, Caridad y Control Social. Las Sociedades de Beneficencia en la Ciudad de Buenos Aires, 1880-1930. Tesis de Maestría presentada en la Facultad Latinoamericana de Ciencias Sociales (Flacso). Buenos Aires, 1990. 
goría de "pobres" (12). Si bien se logran con esos trabajos «instantáneas" más o menos convincentes, la sobrevaloración de las mismas perturba, a nuestro juicio, el análisis de otro tipo de prácticas, constantes y por lo tanto menos espectaculares, que perseguían fines similares (disciplinamiento y normalización) y que estaban atravesando el cuerpo social en las principales ciudades de la Argentina de esa época. Es decir que, si bien es cierto que en determinadas circunstancias históricas de agitación y contestación social (crisis), las prácticas que se llevan adelante desde los ámbitos de poder para combatirlas, suelen ser especialmente violentas, éstas no son únicas ni excluyentes. En épocas de sociedad normal o paradigmática -adoptando un lenguaje de acervo khuniano- las ideologías hegemónicas, actúan cotidianamente, y con ellas y a través de ellas, «el poder se hace armónico en el sentido homogéneo y cohesivo a la sociedad" (13).

La creación de un sistema institucional de asistencia benéfica a los pobres urbanos, fue una de las ideas con más consenso dentro de la clase dirigente de la época, aunque, por supuesto, parte de ellos eran partidarios de dar respuestas exclusivamente represivas a los nacientes y aún desarticulados planteamientos sociales de los sectores populares. De hecho se produjeron, especialmente en la primera década del siglo, manifestaciones de poder duras y violentas. Sin embargo, creemos que éstas últimas fueron excepcionales, diríamos que casi extemporáneas, y pueden rastrearse en su origen dentro de los grupos menos "modernos» de la élite. En parte, esta línea discursiva que apunta al mantenimiento de prácticas políticas consideradas obsoletas (entre otros por los criminólogos positivistas) es, paradójicamente, absorbida en algunos puntos específicos por el discurso benéfico. $\mathrm{Si}$ el ejercicio racional y sistemático de la beneficencia era uno de los pocos medios eficaces para ejercer la vigilancia de los pobres urbanos, moralizarlos y canalizar su fuerza laboral hacia el mercado de trabajo, ello no implicaba que ante la existencia de grupos impermeables a la práctica caritativa no se recurriese a la violencia. La represión se complementa de esta manera con la

(12) Cfr. por ejemplo, Ricardo Falcón. El Estado y la Cuestión Social, Rosario, Cricso, 1986; Juan SURIANO, Trabajadores, anarquismo y Estado represor, Buenos Aires, Centro Editor de América Latina, 1988, y Juan SuRIANO, "La huelga de inquilinos de 1907 en Buenos Aires". En: Sectores populares y vida urbana. Buenos Aires, Clacso, 1984.

(13) Enrique MARI, "Racionalidad e imaginario social en el discurso del orden". En: Enrique Mari y otros. Derecho y psicoanalisis. Buenos Aires, Hachette, 1987, pág. 70. 
búsqueda de consenso. Si el desafío que se le presentaba a las sociedades de beneficencia era el de controlar asistencialmente los efectos de la modernización para que los actores perjudicados no se precipitaran a soluciones extremas de revuelta social, entonces era imprescindible encontrar o inventar un discurso propio que contuviese la idea de represión. La represión y el uso de la violencia se reservaban, en la lógica del discurso caritativo, solamente para los grupos que no ingresaban en el juego benéfico. Es en este aspecto que el discurso benéfico permite contener derivaciones represivas. Con esta lógica argumental, que establecía que el que se negaba a ser asistido y normalizado por prácticas caritativas, debía ser reprimido por medios violentos, se estructura el sistema de asistencia. Es una distinción importante, porque de esa manera el uso de la violencia se discrimina y la represión, cuando ha de ejecutarse, cumple objetivos específicos. Las sociedades de beneficencia estarán a cargo de la recolección de la información necesaria para ejecutar una represión adecuada. Desde el inicio, hubo intentos serios para lograr la unificación de la asistencia y la coordinación de las tareas caritativas, y si bien la centralización total nunca se alcanzó, la coordinación parcial de actividades benéficas (en la Ciudad de Buenos Aires primero y en el resto de las ciudades importantes del país, después), fue un hecho. Comienza a aplicarse dentro de las sociedades de beneficencia un sistema de registro múltiple y permanente. Información y más información. Los grupos a los que las sociedades accedían (que eran a todas luces -o sombras- los que entorpecian potencialmente la funcionalidad del proyecto de Orden y Progreso), se tornaban a partir de la práctica de las sociedades, en objetos de estudio. Los individuos que se amontonaban en "sucias, tenebrosas y hediondas covachas" pasan a ser una suma de datos estadísticos acumulados en una limpia ficha de archivo.

No hay individuo, por retrógrado que sea, que no reconozca la trascendencia y necesidad de las prolijas investigaciones que se hacen entre las clases obreras a fin de salvar la paz social, amenazada en los cimientos de su secular construcción, por la revolución social que se dibuja en los horizontes de nuestra época (14).

(14) Telasco Castellanos, "Leyes protectoras de la infancia y de las mujeres". En: Julio PHILIPPI (Ed.). Cuarto Congreso Científico (Primero Panamericano). Trabajos de la VII sección. Ciencias Económicas y Sociales. Realizado en Santiago de Chile, entre diciembre de 1908 y enero de 1909. Santiago, Ed. Barcelona, 1911, pág. 102. 
Se intenta así, por medio de la estadística (técnica en la que los intelectuales positivistas habían depositado una confianza ciega), individualizar el desorden y al hacerlo se pretende que también se individualice el crimen, la vagancia y la posible $-y$ tan temida - revuelta. Los sectores populares urbanos, se convierten en algo codificable, y en consonancia con la idea de orden, pasibles de ser estudiados $y$, por lo tanto, previsibles. Todo aquel que se ocupaba del tema social urbano creía, tarde o temprano, que los problemas planteados por la llamada "cuestión social" se iban a ver solucionados en gran parte con la organización de un sistema de beneficencia que previniendo los males, descansase en "un buen servicio de investigación» (15). En consecuencia, las prácticas políticas desarrolladas por las sociedades de beneficencia, son seguro menos espectaculares que las que poseen claras connotaciones represivas, pero creemos más contundentes, en la medida en que logran distribuir los efectos del poder por la totalidad del cuerpo social.

Por otro lado, los proyectos represivos más ambiciosos de la época eran, en su gran mayoría, o bien de aplicación materialmente imposible, o bien de ejecución muy costosa. Recluir a gran cantidad de gente en prisiones, por ejemplo, era entre otras cosas, antieconómico. La infraestructura represiva necesaria para llevarlos adelante era algo que estaba muy lejos de alcanzarse» (16). Además, su construcción resultaba demasiado onerosa y los beneficios que podían esperarse del mismo eran casi nulos: ya en esos años se tenía la certeza de que el tener encerradas una importante cantidad de personas con el único fin de apartarlas de la vida social significaba, en la medida en que no cabía esperar su regeneramiento, despilfarrar el dinero. Por ello, gran parte de los recursos disponibles se dedican a financiar la construcción de un sistema de beneficencia que prometía ser económicamente ventajoso. Y el mismo resultó serlo en varios sentidos. En primera instancia, porque permitía disciplinar y calificar mano de obra infantil en los asilos. El encierro masivo, desde las dos

(15) Severo LAFOnTE, "La beneficencia organizada". En: Buenos Aires, Año IV, 166,12/6/1898, pág. 3.

(16) Así, por ejemplo, cuando en 1882, ante la insistencia del Intendente Alvear la policía detuvo a gran cantidad de vagos y mendigos invocando un decreto de 1823, que prohíbia la mendicidad sin un certificado del Jefe de Destacamento que acreditase la indigencia, éstos lograron una pronta libertad por dos motivos. El primero de características legales, ya que el decreto invocado carecía de vigencia. El segundo motivo era un poco mas práctico: el asilo de mendigos no tenía capacidad para alojarlos. Adolfo Rodrígufz, Historia de la Policia Federal Argentina 1880-1916. Buenos Aires, Editorial Policial, 1980, tomo V. págs. $43-46$. 
últimas décadas del siglo pasado, sólo va a aplicarse en la medida en que fuese considerado redituable. En consecuencia sólo va a llevarse adelante con los niños, es decir, no con una mano de obra pasada o presente, sino futura. Desde 1880, decenas de asilos y orfanatos son fundados por las sociedades de beneficencia para alojar a los niños de las familias de los sectores populares porteños. Se argumentaba que cualquier suma de dinero que se invirtiese en asilos o escuelas para niños iba a ser menor que la necesaria para corregirlos una vez adultos. De manera tal que el sistema benéfico, aparentemente costoso, era en realidad económicamente ventajoso.

En último análisis, los niños descuidados por la familia $\mathrm{A}$ o $B$, no perjudican con su suerte futura, tan solo al hogar del que proceden, sino a la comunidad entera, ya que es ella quien deberá sufrir un rebajamiento de su nivel moral y un desequilibrio en su economía, sosteniendo mañana al que consume y no produce, porque habita el hospital, la cárcel o el asilo. He aquí cómo la crueldad y el abandono, de delitos privados se convierten en crímenes públicos (...) si hay algún punto donde la filantropía preventiva puede ejercitarse con la seguridad de ganar diarias victorias, es sin duda la infancia (17)

El ejercicio de la beneficencia, pone a los niños de los sectores populares en el centro de la escena. Los mismos serán el vehículo que posibilite a las distintas sociedades, el acceso al hogar de sus padres, para ejercer allí su acción moralizadora.

En líneas generales, los niños de los sectores populares, son siempre visualizados por los sectores dominantes, en dos sentidos, según sea la relación en que se encuentren respecto del aparato institucional. En primer término, si se educaban en las escuelas, si eran asistidos en su domicilio regularmente por alguna sociedad de beneficencia o, mejor aún, si estaban pupilos en algún asilo dirigido por las mismas, eran considerados entonces un elemento clave del proyecto de disciplinamiento social general, ya que realimentaban y reproducían el proceso. En segundo término, si no se lograba que el "edificio social» adquiriera una consistencia tal que impidiera que los niños se escabulleran a su acción; es decir, si el tejido social permitía que algunos grupos de niños lograran sortear la red de instituciones que trataban de cercarlo, esquivar las prácticas que emanando de esa red pretendían to-

(17) Ernestina LóPez de Nelson, "Nuevos ideales filantrópicos". En: Boletín del Museo Social Argentino. Año III, nos 25 y 26 enero/febrero de 1914, pág. 75. 
marlo y normalizarlo, se convertía en un peligro potencial y por lo tanto debía ser eliminado o aislado lo más rápidamente posible. Bartolomé Novaro, que entre otras cosas fue presidente del Círculo Médico Argentino, de la Sociedad Científica Argentina y socio fundador de la Cruz Roja, resume estas posibilidades con una elocuencia notable:

Niño: eres la luz que alumbra a tu hogar con colores de alegría y de esperanza; no te apagues. Tal vez llegues a brillar como un faro inmenso, si se realizan las aspiraciones de quienes guían tus primeros pasos. Pero si tus padres te faltan, si esta santa institución no puede ampararte; si tus manos criminales o las ideas de tu cabeza delirante han de iluminar los horizontes de tu Patria con resplandores de incendio... apágate más bien (18).

Pero el sistema benéfico no era redituable solamente porque permitía el ingreso de algunos grupos de niños de las capas inferiores de los sectores populares urbanos a un nuevo circuito productivo. También lo era, en segunda instancia, porque favorecía el crecimiento de la iniciativa privada en el dominio de la asistencia social. El sistema benéfico permitía poner en funcionamiento, para acceder a la intimidad de los sectores populares urbanos con el fin de obtener información, moralizarlos e integrarlos, una importante y poco onerosa estrategia institucional: las damas de caridad eran agentes gratuitos de un sistema institucional que, a su vez, en gran parte era financiado por particulares (19).

\section{LOS BENEFACTORES}

Para que los objetivos benéficos pudiesen ser cumplidos, era indispensable llegar hasta los pobres, ejercitar las tareas de asistencia y control en el mismo hogar de los sectores populares, en

(18) Bartolomé Novaro, "Por la infancia desvalida". En: Buenos Aires, año IV, ne 182, 2/10/1898, pág. 12

(19) En algunas sociedades, el dinero recaudado por esos medios alternativos podía llegar a ser mucho más sustancioso que el que aportaba el Estado en forma regular. La cantidad de dinero ingresado en los balances de las Conferencias de Damas de San Vicente de Paul entre los años 1889 (año de la fundación) y 1914, discriminado por su origen (Estado y Particulares), nos demuestra que mientras el Estado aportó entre esos años (o bien por leyes especiales o por aportes de la Lotería de Beneficencia) alrededor de dos millones de pesos moneda nacional, los particulares (por todo concepto), habían contribuido con más de trece millones de pesos, Conferencias de SEÑoras de San Vicente de Paul [3]. 
sus casas, con su familia. Ésta iba a ser la misión de los militantes benéficos. La nueva estrategia de disciplina social en la que las sociedades de beneficencia iban a participar, encuentra en las ideas de Leopoldo Mallibeau, director del Museo Social de París, su expresión más acabada. La asistencia -decia Mallibeaudebía ser una función de la vida cívica comparable, como carga, a la del servicio militar obligatorio: así como todo ciudadano estaba obligado a ser durante un tiempo de su vida soldado, cada uno de los que, a juicio de los convecinos, reuniera ciertas condiciones de moralidad e instrucción, estaba obligado «a prestar el servicio de asistencia, en la sección del barrio que se le designe o el grupo de familias a que se reduzca su vigilancia, visitando diariamente, no solamente las casas de los enfermos, sino también aquellas que por circunstancias especiales pueda suponerse que necesitan asistencia pública» (20). Imaginemos por un momento la idea de Mallibeau en funcionamiento: es, sin duda, el ideal de una ciudad científicamente organizada, bien gobernada, donde nada hubiese podido caer fuera de la mirada de un otro que poseía el saber suficiente para interpretar lo que estaba mirando y el poder necesario como para no tener que volver a verlo.

Todas las sociedades benéficas poseen una característica excluyente: están integradas y son dirigidas, coordinadas y supervisadas en su desarrollo, casi en exclusividad, por mujeres (21). El engranaje más importante para el buen funcionamiento de la estrategia montada en torno a la caridad, fueron las llamadas "damas de beneficencia». Desde la explosión benéfica originada alrededor de 1880 se abre a la mujer porteña un espacio de participación social que tenderá a hacerse necesariamente masivo. Puede argumentarse, con razón, que las mujeres siempre se hicieron cargo de las instituciones dedicadas a la asistencia de los huérfanos y ancianos: de hecho la Sociedad de Beneficencia de Buenos Aires fue creada en 1823 por Rivadavia y en esa fecha su dirección también estuvo a cargo de mujeres. Pero la multiplicación de las sociedades implicó la multiplicación de los

(20) Leopoldo Mallibeau, "Las Conferencias del Señor Mallibeau". En: Boletín del Museo Social Argentino. 1912, año 1, n² 9, pág. 402.

(21) Cintya Little hacía notar, a nuestro juicio acertadamente, en un artículo publicado en 1985, que el hacer beneficencia, dedicarse a tareas educativas, o militares en algún movimiento feminista, fueron las únicas posibilidades de participación en el campo social abiertas a la mujer entre 1860 y 1926. Ver Cynthia LITTLE, "Educación, filantropía y feminismo: partes integrantes de la femineidad argentina, 1860-1926". En: Asunción LAVRIN, (Comp.). Las mujeres Latinoamericanas. Perspectivas históricas, México, Fondo de Cultura Económica, 1985, págs. 271-292. 
espacios de participación femeninos. No podrian ser, desde ese momento, sólo las esposas o hijas de los más caracterizados miembros de la élite las únicas personas que participaran del manejo de las nuevas y numerosas instituciones de beneficencia: serían necesarias miles de mujeres provenientes de un espectro social más amplio las que tuvieran que dedicar su tiempo y su trabajo a tareas "caritativas». La expansión del sistema les obliga a ensanchar su base social. La preocupación por reclutar mujeres de la incipiente clase media y de las capas superiores de los sectores populares para la causa de la beneficencia fue constante desde 1890 en adelante.

La representación imaginaria de una dama de beneficencia correspondía, sin duda, a la de una matrona aristocrática. Pero debe entenderse que ellas sólo eran la punta del iceberg. En todo caso esa representación imaginaria era utilizada sistemáticamente como anzuelo para reclutar militantes. Haciendo beneficencia las mujeres de la ascendente clase media podían compartir tareas y lugares, y hasta competir con sus pares, de las familias más tradicionales de la sociedad porteña. Era una invitación más que seductora, sobre todo si se pensaba que desde allí se iba a ir creando paulatinamente "una nueva y legítima aristocracia femenina que se imponga como ejemplo y modelo a la generalidad» (22). Las mujeres encuentran en la beneficencia una clara posibilidad de acceder a una participación social que antes les estaba vedada por su sexo. En la lógica del discurso benéfico, la vida pública quedaba dividida en dos grandes esferas: la política y la moral. Y si la primera era coto de los hombres, la segunda lo era de las mujeres. Esta concepción del rol específico de la mujer en la vida social se extiende en la sociedad porteña por diversos canales (publicaciones periódicas, escuela, etc.), hasta hacerse hegemónica.

Es necesario destacar que las sociedades de beneficencia apuntaban siempre a lograr un ensanchamiento de sus adherentes fuera de los círculos del dinero. El concurso de las capas superiores de los sectores populares urbanos de la ciudad de Buenos Aires (empleados, pequeños comerciantes, etc.), en la estrategia benéfica montada por los sectores dominantes de la misma ciudad, en el segmento de los benefactores, es un punto indiscutible y puede ser rastreado en diversas fuentes. En efecto, cuando Ricardo del Campo, pensó en las reformas que debían introdu-

(22) J. Abasolo, "Ministerio social de la mujer". Revista Nacional. Julio de 1904, n 38 , págs. 94-95. 
cirse en el sistema de beneficencia, a fines del siglo pasado, propuso que se creara un Consejo de beneficencia - a semejanza del Consejo Nacional de Educación- y que sus miembros fueran elegidos por el voto popular «junto con los integrantes del Consejo Deliberante» (23). En el mismo sentido, el artículo 14 del decreto municipal que crea el Patronato de la Infancia, señalaba taxativamente que era necesario favorecer la creación de sociedades protectoras de la infancia en las diversas parroquias del municipio, «dándoles origen popular y acordándoles todo el concurso moral y material que necesiten" (24). Demanda de participación popular que se reitera cuando Emilio Coni propone como modelo del mismo Patronato la «Union Française pour la Défense et Tutelle des Enfants Maltraités ou en Danger Moral», ya que si se copiase la estructura organizativa de esa Unión «los beneficios sin duda alguna aumentarian, porque tendría ella un concurso popular importante» (25).

Por su parte, el análisis de las nóminas de las muchas colectas multitudinarias que organizaban anualmente las sociedades benéficas más importantes revela esa participación: la gran mayoría de las donaciones que se recibían no superaban más que unos pocos pesos de moneda nacional (26). En otra colecta multitudinaria, organizada por el Consejo Nacional de Educación para las escuelas de la Capital Federal, que contó con la participación de 80.000 niños y 2.000 maestros, se recolectaron en un sólo día 60.660 pesos, y se aclaraba que si bien la cifra era por sí sóla elocuente, lo era mucho más si se consideraba que a ella se había llegado «no con las donaciones elevadas de gente pudiente, sino con las pequeñas contribuciones del pueblo, de millares y millares de personas pobres, niños, jóvenes, ancianos, hombres y

(23) Del Campo [7].

(24) Intendencia Municipal de la cludad de Buenos Aires, Patronato y Asistencia de la Infancia, en la Capital de la República. Buenos Aires. El Censor, 1892, Asimismo, en los considerandos del Decreto Municipal que autoriza a la comisión de higeniestas que habían trabajado en el proyecto de fundación del Patronato de la Infancia, a dirigir y organizar el mismo, se señala que: "La tutela y protección de los niños abandonados, no es una función del resorte exclusivamente oficial, sino que corresponde a la filantropía y no puede ser eficaz ni duradera sin la cooperación del pueblom.

(25) Emilio CONI, "Niños maltratados o en peligro moral". En: INTENDENCIA Municipal de la CiUdad de Buenos Aires, Idem, pág. 400.

(26) Patronato de la Infancia. Día de los niños pobres, Buenos Aires, S/E, 1909. Sobre este punto puede verse, también, PaTronato DE LA INFANCIA, Bodas de Plata de la Alcancía 1905-1930. Buenos Aires. Álvarez, 1935; ConfERENCIAS DE SEÑORAS DF SAN VICENTE DE PAUL, Memoria de la "Semana del pobre" realizada en la Capital en junio de 1925. Buenos Aires, El Propagador Cristiano, 1916. 
mujeres». Pero lo más interesante del artículo publicado por $E l$ monitor de la Educación Común son los comentarios hechos por los niños que participaron de la colecta. En ellos puede apreciarse el alto grado de adhesión que recibian este tipo de manifestaciones benéficas dentro de los sectores populares:

Golpeamos en una casa; como no salía nadie subimos, volvimos a golpear y salió una señora que nos hizo entrar y nos dijo que ella iba a contribuir con un poco, porque ella era pobre y no podía; nos dio un peso y nosotros le agradecimos porque vimos la buena voluntad de la señora.

Entramos en una casa, en seguida nos rodearon los vecinos, todos quisieron dar algo, quien centavos, quien pesos, según podian (...) Entre otras escenas recuerdo la de un tugurio desmantelado, careciendo de lo más indispensable; en él una mujer, madre de cinco niños, agobiada por la fatiga y los niños descalzos y mal abrigados y desaliñados (...) la pobre mujer nos dijo que su esposo había donado ya un día de sueldo, pero que ella también quería hacer algo por esos niños abandonados (...) y sacando de una cajita 0.35 centavos, que era lo único que poseía en ese momento, nos lo dio. Nuestra profesora (...) pidió a la buena mujer que guardara ese dinero que ella lo pondría en su lugar, pero tanto insistió y rogó, que no le privaran hacer ese dulce sacrificio, que fue necesario aceptarlo (27).

También puede apreciarse lo amplia que era la base de donantes en los agradecimientos que las distintas sociedades de beneficencia hacían en sus memorias o informes y en diversas fuentes literarias (28)

Las diversas tácticas empleadas por las sociedades de beneficencia para reclutar adherentes y militantes dentro de la clase media y en las capas superiores de los sectores populares urbanos, tuvieron un llamativo éxito: de hecho, en las primeras décadas del siglo la ciudad de Buenos Aires contó, gracias a la participación de miles de mujeres, con uno de los sistemas de beneficencia más desarrollados del mundo. Es indudable, a nuestro juicio, que si esa participación es posible se debe a que la sociedad porteña de las primeras décadas del siglo se encuentra literalmente atravesada por la idea de progreso. La noción de

(27) "La catástrofe chilena. Homenaje de las escuelas públicas argentinas". En: El Monitor de la Educación Común. Año XXVI, tomo XXIII, nº 405, 30-09. 1906, pág. 280-346.

(28) Cfr. Roberto GaCHE, Glosario de la farsa urbana. Buenos Aires, Cooperativa Ed. 1920. 
progreso individual, si bien parte de los núcleos dirigentes e ilustrados de la sociedad, es adoptada, obviamente, por la ascendente clase media y desde alli se desliza paulatinamente hacia una gran parte de los sectores populares de la ciudad. Si en esos grupos, el progreso era leído inequívocamente como ascenso social, sus integrantes tenían en la beneficencia una única y accesible manera de establecer una diferenciación más o menos clara entre su pasado pobre y su presente benefactor. Los hombres podían acceder a ese nuevo status aportando parte de su dinero y las mujeres parte de su tiempo. Consideramos que es necesario tener presente que participar de la beneficencia -entendiendo por esto el dar dinero u otras cosas para alguien que presume más pobre y necesitado- funcionó, dentro de las capas superiores de los sectores populares urbanos, como un síntoma inequívoco de "pertenencia a». Aquel que participaba en ella del lado de los benefactores, podía considerarse parte del orden y del progreso.

\section{LA CONSTRUCCIÓN DE UNA LÓGICA ASISTENCIAL}

Como señalamos, la practica benéfica pronto pasó a ser considerada por los sectores dominantes, como una importante herramienta en la construcción del consenso social necesario para el normal desenvolvimiento del proyecto de organización de una nación moderna. Las sociedades de beneficencia intentarán actuar como poleas de transmisión de un conjunto de valores considerados adecuados e indispensables por los sectores dominantes para la formación de una "unidad ética» que posibilitará el gobierno de la sociedad. Esta "unidad ética» era visualizada como la base esencial para la constitución de una nacionalidad, y en ella no podía haber lugar para una multiplicidad de prácticas y/o valores sociales que los sectores dominantes veían cristalizadas en las capas inferiores de los sectores populares urbanos. Pero dichas prácticas sociales no podían ser atacadas correctivamente desde el derecho penal: escapando al derecho positivo constituían "vicios" y no "delitos" en sentido estricto. Algunos criminólogos positivistas subsanaron el problema. José Ingenieros, el intelectual más notable del positivismo argentino de la época, encontraba que en la sociedad se daban dos tipos de delincuencia, la "delincuencia criminal" y la "delincuencia natural». La primera, de sencilla definición, implicaba una violación expresa de las leyes penales vigentes (delito o criminalidad), en tanto que para caer en la segunda era necesario mantener una línea de conducta 
pausible de ser considerada antisocial con respecto al criterio ético de un ambiente dado (vicios). En otras palabras, el vicio, siendo siempre inmoral, podía no ser un delito para la ley. Ingenieros, notoriamente influenciado por la escuela criminológica italiana de la segunda mitad del siglo XIX (29), reconocía que la moral reflejada en la ley y en las instituciones era relativa, es decir que no era la moral de toda la colectividad sino la del grupo dominante y que nada autorizaba a creer que la moral dominante en cada época y lugar fuera mejor a las demás, pero establecía que las transgresiones a la misma eran hechos antisociales, "actos nocivos al agregado social». Los delincuentes naturales eran aquellos que tenían una probada incapacidad para adaptar su conducta a las condiciones que, en cada sociedad, «limitan la lucha por la vida». Por lo tanto debían ejercitarse contra los mismos actos de defensa social, pero teniendo en cuenta que esas formas de criminalidad debían reprimirse recordando que, por definición, el mal de hoy puede convertirse en el bien del mañana y entonces «esa duda saludable mitigará el rigor de los honestos hacia los tristes que viven arrastrándose al margen de la moral o de la ley, permitiendo que nos defendamos de ellos con mano segura pero con serenidad ecuánime" (30).

La manera de atacar las diversas formas que adoptaba la delincuencia natural, los problemas que se oponían a la necesaria "unidad ética» que los sectores dominantes creían ver subir «como una ola de fango que amenaza subvertir todo: familia, sociedad, nación", no podía ser, entonces, la represión violenta. Una medida de ese tipo hubiese generado infinidad de resistencias y respuestas del mismo tenor y por lo tanto la solución debía ser la puesta en marcha una cruzada de "propaganda de una moral positiva,

(29) Para un estudio del desarrollo de la escuela citada, puede verse, José Luis PESET, Ciencia y marginación, Barcelona, Crítica 1983, en particular el capítulo $\mathrm{V}$, "Un nuevo país: Italia".

(30) Los "delincuentes naturales" son los parásitos de la escoria social, los fronterizos de la infamia, los comensales del vicio y de la deshonra, los tristes que se mueven acicateados por sentimientos anormales; espíritus que sobrellevan la fatalidad de herencias enfermizas y sufren la carcoma inexorable de las miserias ambientes. (...) Viven adaptados a una moral aparte, con panoramas de umbrosas perspectivas, esquivando los clarores luminosos y escurriéndose entre las penumbras más densas; fermentan y pululan en el agitado aturdimiento de las grandes ciudades modernas, retoñando en todas las grietas del edificio social y conspirando sordamente contra su estabilidad (...) Es una horda extranjera y hostil dentro de su propio terruño". José INGFNIEROS, "El delito y la defensa social" En: Archivos de Psiquiatria, criminologia y Ciencias A/ines, año VIII, tomo VIII, 1909, págs. 207-217. El tema es tratado también por el mismo autor en los capítulos iniciales de Criminología. Buenos Aires, Rosso, 1916. 
socialmente establecida" (31). Las sociedades de beneficencia van a ser las encargadas de llevar adelante gran parte de esta cruzada de moralización.

Las militantes benéficas cumplen, de hecho, la misión del "vecino respetable" que ejemplificaba Mallibeau en el trabajo citado anteriormente realizando visitas al domicilio de sus asistidos. Muchas eran las instituciones que recomendaban a sus socias la ejecución de dicha práctica e incluso algunas, como las Conferencias de Señoras de San Vicente de Paul, la prescribían estatutariamente (32). Una de las integrantes de esta última institución había escrito un largo trabajo acerca de cómo debían realizarse las mismas (33) y la sociedad llevaba un detallado recuento de las visitas que hacían sus socias. En los primeros veinticinco años de su existencia en Argentina (1889-1914), las Conferencias de Señoras de San Vicente de Paul, llevaron a cabo una importante "cruzada" de moralización haciendo visitas domiciliarias. Solamente en la ciudad de Buenos Aires, y por intermedio de las 35 Conferencias que se hallaban confederadas, habían asistido a 120.351 familias, lo que equivalía según datos de las mismas Conferencias, a un total de 333.588 personas. Para hacer posible esta asistencia realizaron, más de dos millones de visitas domiciliarias (34) lo que da un promedio de 6,02 visitas por persona asistida. Las Conferencias participaron activamente en la consumación de 8.357 matrimonios, 9.236 legitimaciones, 30.791 bautismos o primeras comuniones de niños, 15.573 bautismos o primeras comuniones de adultos y habían logrado uregenerar» a 1.781 jóvenes (35). El total de personas alcanzadas por

(31) CONFERENCiaS de SeÑoras [3], pág. 58. $\mathrm{s} / \mathrm{f}$. folleto.

(32) Conferencias de Señoras de San Vicente de Paul. Estatutos. Buenos Aires,

(33) Concepción Arenal, El visitador de pobres, Buenos Aires, Emece, 1941.

(34) Es importante destacar que los datos registramos por las distintas Conferencias de la ciudad de Buenos Aires, no son homogéneos. Así, mientras existen registros en todas las Conferencias del total de personas asistidas y sólo en una de ellas faltan los datos correspondientes al total de familias asistidas, quince Conferencias no registraron el total de las visitas domiciliarias realizadas por sus socias. De manera tal que las 2.009.127 corresponden al trabajo de las socias de 20 Conferencias. Es probable, entonces, que el promedio real de visita domiciliaria persona asistida, sea sensiblemente superior al establecido por nosotros.

(35) Como en la nota anterior debemos aclarar que doce Conferencias no registraron datos en el rubro "Jóvenes regeneradas"; se apuntaba en este rubro a las mujeres que habían sido alejadas del ejercicio de la prostitución; tres no lo hicieron en la legitimación de hijos y 16 en la realización de matrimonios. Asimismo Cuatro Conferencias no registran los bautismos y primeras comuniones de niños y ocho no lo hacen en los bautismos y primeras comuniones de adultos. Por lo tanto es probable que el promedio real de tareas realizadas-personas asistidas, sea también superior al establecido por nosotros. 
las tareas de moralización practicadas por las Conferencias - suponiendo arbitrariamente que se dirigieron siempre a diferentes individuos - sumaron en ese cuarto de siglo, contabilizando como dobles los matrimonios, 74.095. Promediando, entonces, vemos que estas tareas dejaron sentir sus efectos sobre un 22,2 por ciento de las personas asistidas (36).

En su desarrollo, la práctica de la beneficencia se entronca y da sustento teórico a la naciente noción de «prevención».

Haceis señoras la profilaxis de los enfermos y se necesita la de los sanos: bueno es cuidar el mal producido, pero es mejor prevenir el que todavía no se ha manifestado (37).

La misma, asociada a la práctica social caritativa, va a generar una técnica política en la que la miseria, la necesidad o la pobreza, tiende a dejar de funcionar como principio de insurrección, para pasar a ser, paradójicamente, un medio de integración social (38). La prevención — de la tuberculosis, del alcoholismo, del incesto, de la prostitución, del socialismo, del anarquismo, de la delincuencia, lo mismo da - va a pasar a ser una de las principales funciones de la beneficencia.

La multiplicidad de labores desarrolladas por dichas sociedades, pasaron a ser un arma fundamental dentro del arsenal que los sectores dominantes pusieron en juego para intentar el acercamiento a los sectores populares urbanos y, por supuesto, la posterior moralización (normalización) de los mismos. Las obras de asistencia, que no eran otra cosa que tácticas políticas tendientes a la moralización, al «regeneramiento moral de los asistidos", van a generar una particular lógica asistencial que, en gran medida, condicionará el desarrollo del sistema de asistencia social en las siguientes décadas.

El presidente Roque Sáenz Peña, en su discurso ofrecido en los actos celebrados con motivo de la inauguración del asilo Saturnino Unzué, opinaba que el problema de la desigualdad social hacía necesarios esos "hermosos movimientos que llevan el consuelo y la esperanza a los vencidos por la vida, porque al reparar así las injusticias del destino, crean entre las clases extremas de la sociedad vínculos de solidaridad y armonía" (39). Ahora

(36) Conferencias de Señoras [5].

(37) Mallibeau [20], pág. 346.

(38) Jacques Donzelot, La policía de las /amilias, Barcelona, Pretextos, 1982. pág. 67.

(39) Ruque Sáenz Peña, "Discurso ante la inauguración del asilo Saturnino Unzué". En Carlos Correa Luna, Historia de la Sociedad de Bene/icencia. Buenos Aires, Sociedad de Beneficencia, 1925, pág. 268. 
bien, para que esos "hermosos movimientos» que reclamaba Sáenz Peña no subvirtieran el orden jurídico y social establecido, era conveniente ubicarlos en un escalón jurídico particular y distintivo. Por eso, si bien se establecía que en el fuero interno no podía haber diferencias entre los deberes de justicia y los de caridad - respecto a la fuerza con que obligaban y a la responsabilidad que imponían- ambos tenían distintas características. El cumplimiento de los deberes de justicia podía exigirse y los derechos a los que daban origen, ejercitarse, pero los deberes de caridad, quedaban abandonados a la conciencia de cada uno y por lo tanto no creaban derechos (40). En consecuencia, si era necesario que los sectores populares se vieran favorecidos por el accionar de la beneficencia, también lo era señalar claramente que los mismos no tenían ningún derecho a exigirle, ni al Estado ni a nadie, un mejoramiento en su calidad de vida. Es este un problema importante y su resolución acarreará consecuencias determinantes para el desarrollo de la asistencia pública en Argentina: cuando a mediados de la década de 1920 las sociedades de beneficencia se inserten en los hospitales públicos de Buenos Aires, la lógica asistencial que las guíe será idéntica (41).

Una de las características del discurso benéfico era, entonces, que el beneficiado no tenía derecho a reclamar la asistencia de la que era objeto. Es en este sentido que la beneficencia y la filantropía tienden a establecer, como acertadamente señala Hugo Vezzetti, la lógica paradoja y perdurable de la asistencia pública en Argentina: el necesitado va a tener acceso a la asistencia, en la medida en que renuncie a considerarla como un derecho (42).

Es obvio que esas concesiones no constituyen derechos. Derecho, en estricta justicia, no hay más que uno: el que para sí y para los suyos, tiene todo hombre al producto de su esfuerzo, de su capacidad y de su trabajo (43).

El pobre, el que se beneficiaba de la acción caritativa, no tenía ningún derecho que reivindicar. Como pobre solamente

(40) Félix Martín y Herrera, Curso sumario de moral Lecciones dadas en la Escuela Normal Buenos Aires, Astrada, 1899. Obra aprobada como texto escolar por el Consejo Nacional de Educación.

(41) Eduardo Ciafardo, "De la Dama de Caridad a la Asistente Social. El surgimiento de los servicios hospitalarios de Asistencia Social en la ciudad de Buenos Aires, 1920-1936". La Plata, Mimeo, 1990.

(42) Hugo Vezzetti, La locura en Argentina. Buenos Aires, Paidós, 1984, págs. 22.

(43) Conferencias de. Señoras de San Vicente de Paul [3], pág. 78. 
podía ser objeto de una preocupación impuesta por una ley al Estado, y entonces el necesitado nunca podía ser considerado como el sujeto sino como el objeto de la previsión social (44). Pero, y ésto es importante, sujeto u objeto de la previsión el pobre al que no se le exigía pagar con dinero la asistencia que recibía a diario, y teniendo en cuenta que no estaba ejercitando un derecho, tenía el deber de estar agradecido a los que teniendo dinero lo destinaban a obras de caridad.

Los 50.000 seres que a diario reciben el cuidado de la hermana, o sopas de convento, o ropas de asilo, o enseñanzas de madre o ejemplos que levantan, o ayudas que protegen, tienen fundamento para prodigar sus gratitudes (45).

Entonces el asistido aceptaba a su benefactor «en una relación especular en la que la alegría del donante que hace una ofrenda sin obligación está en reciprocidad con el agradecimiento del asistido salvado de la necesidad por un socorro al que no tiene derecho" (46). Este juego rígidamente pautado que se establecía entre asistente-asistido tenía la virtud de devolver a los sectores dominantes, la imagen tranquilizadora de una relación de tutela, en la que el beneficiado, sea éste, mendigo, niño, hombre, sano o enfermo, es "asimilado a un estatuto de minoridad jurídica" (47). La gratitud del asistido debía expresarse, repitámoslo, en la aceptación de pautas culturales de contenido moralizante (casamiento, reconocimiento legal de los hijos, obtención de un trabajo estable, etc.) y en la renuncia a participar de practicas políticas de contenido "disolventes» (anarquismo).

\section{CONSIDERACIONES FINALES}

La beneficencia, en tanto aparato institucionalmente estructurado, aparece, en nuestra opinión, como una de las puntas de aquellos que buscan la ocupación concreta de un espacio territo-

(44) Hilarión Larguia, "La previsión social». En: Congreso Internacional de mutualidad y previsión social Buenos Aires, Ministerio de Agricultura de la Nación, 1917, pág. 64.

(45) Alberto, Meyer Arana, "La beneficencia en Buenos Aires". En: Censo General de la Ciudad de Buenos Aires, Buenos Aires, 1910, tomo III, pág. 620.

(46) CASTEL, [10], pág. 141.

(47) VezzetTi [42] pág. 20. Para una aproximación a la forma de legitimación de este tipo de asistencia por el discurso médico, ver Jean CLAVREUL, El orden médico. Barcelona, Argot, 1983. En particular la Introducción y el capítulo 3, "Los orígenes de la medicina. Mitologías del positivismo"; y Michel FoucAuLT, El nacimiento de la clínica, México, Siglo XXI, 1980. 
rial dado y difusamente delimitado por la idea de ciudad. A partir de la captura de ese macroespacio, contenido en lo urbano, los sectores dominantes tratan de acceder por todos los medios posibles a un microespacio que, desde fines del siglo XIX, los obsesiona: el hogar de los pobres, de aquellos que aparecen y desaparecen diariamente de su vista, que hablan lenguas y dialectos ininteligibles, en fin, el hogar de los otros. El hogar de los otros, no remite solamente a su "casa» o su «habitación», sino también (y fundamentalmente), a su familia, su pasado y sus costumbres. La práctica benéfica se convirtió en una de las herramientas ideales para intentar ese acceso.

El inusitado crecimiento que la ciudad de Buenos Aires sufre a fines del siglo XIX modifica las prioridades y la orientación de la asistencia: no ya ancianos aislados que solicitaban limosna en las calles o grupos de adultos menestorosos, sino miles de niños harapientos que sobrevivian en el límite de la legalidad, que tenían oficios peligrosos, que no asistían a la escuela y que en sus hogares se suponía que los padres o bien no les prestaban la más mínima atención o bien los castigaban brutalmente. En fin, criminales en potencia que tarde o temprano provocarían desórdenes de imprevisible magnitud hostigando constantemente el proyecto de nación moderna. ¿Cuántas cárceles, hospicios y hospitales sería necesario construir para albergar a esos niños en el futuro?

La práctica constante de la beneficencia, ejecutada por miles de voluntarias que recorren todos los días, durante años, la ciudad de punta a punta, visitando personal y tenazmente la vivienda de los otros, ingresando en conventillos, internando niños en asilos o escuelas, etc., permite integrar socialmente a una ciudad que en su crecimiento se estaba escapando peligrosamente hacía límites no muy precisos. Si, como señala Deleuze, las instituciones no son fuentes o esencias, ni exterioridad, sino simplemente prácticos, mecanismos operatorios que no explican el poder, puesto que presuponen las relaciones y se contentan con fijarlas (48), podemos decir, entonces, que Buenos Aires va a aparecer integrada, tanto discursiva como socialmente, desde una práctica institucional cuyo efecto político fue al mismo tiempo, "conservador" y "avanzado", ya que combinaba las ideas clasistas del período anterior con las exigencias de control social del nuevo orden industrial (49). La expansión del aparato benéfico va a permitir mantener el orden, la estabilidad y el control de la

(48) Giles Deleuze, "Las estrategias o lo no estratificado: el pensamiento del afuera (poder)". En: Foucault, Buenos Aires, Paidós, 1987, págs. 104-105.

(49) Anthony, Platt: Los Salvadores del Niño o la invención de la delincuencia, México, Siglo XXI, 1982. 
sociedad, conservando, al mismo tiempo, el sistema de clases y la distribución de la riqueza existentes hasta ese momento. La expansión del sistema fue posible, también, porque el ejercicio sistemático de la beneficencia era muy conveniente para el proyecto integracionista de nación: a partir de ella, y por medio de ella los sectores dominantes, pueden acceder a un mundo que antes les estaba, por su propia determinación, vedado: el hogar de los pobres. $Y$ a partir de la información que las sociedades acumulan y suministran constantemente, va a ser mucho más sencillo descubrir "científicamente" cuáles son los grupos en condiciones potenciales de atentar contra la funcionalidad del proyecto hegemónico de nación.

Las cifras que manejamos con respecto a la cantidad de servicios prestados por las distintas sociedades y los análisis cualitativos realizados en torno a las tácticas de acercamiento a los sectores populares empleadas por las mismas, parecen indicar que las prácticas de disciplina y moralidad desarrolladas durante décadas tuvieron necesariamente que ejercer alguna incidencia en la conformación cultural e ideológica de vastos grupos sociales.

Cuando los investigadores analizan el caso ingles llegan, por lo general a la misma conclusión: los intentos de moralización de la clase obrera inglesa por medio de la acción de sociedades de beneficencia o grupos filantrópicos, fueron vanos. Gareth S. Jones, por ejemplo, considera, con respecto a los intentos de moralización de la clase obrera londinense en el último cuarto del siglo XIX, que "los resultados de cincuenta años de actividad misionera cristiana eran insignificantes». En todo caso, la penetración de las sociedades de beneficencia en el hogar de los sectores populares se daba siempre a partir de la mujer de la casa y ademas, cuando los pobres aceptaban los oficios religiosos que la mayoría de las sociedades les ofrecían, era generalmente por razones materiales: si se suprimía la caridad, la congregación desaparecía, "era una curiosa ironía que los pobres tuvieran que adoptar una actitud profundamente utilitarista en el único campo en que la clase media la consideraba inapropiada (50).

Hemos trabajado bajo el supuesto de que una cosa hace al menos difícil si no imposible, adaptar las conclusiones de Jones para el caso porteño: la alta movilidad social existente en la

(50) Stedman G. JoNES, "Cultura y política obrera en Londres 1870-1900 notas sobre la reconstrucción de una clase obrera". En: En Teoría, 8-9. Madrid, octubre de 1981-marzo de 1982, págs. 51-53. Para un acercamiento a una posición contraria a la de Jones para el mismo caso inglés, ver los comentarios de François BEDARIDA, en la discusión del trabajo de Eric HoBSBAwN, "Las clases obreras ingleses y la cultura desde los comienzos de la revolución industrial". En: Louis Bergeron, (Comp.). Niveles de cultura y grupos sociales, México. Siglo XXI, 1977, págs. 211-213. 
Argentina de esa época y la falta de una tradición cultural obrera. Es conveniente tener en cuenta que para el caso argentino, cuando hablamos o indagamos en la formación de una cultura obrera en el lapso que media entre 1880 y 1920, es probable que nos encontremos con la concurrencia de una gran cantidad de impurezas provenientes de los núcleos «civilizados y civilizadores". Es decir que, si bien no puede creerse que el sólo hecho de la existencia de un determinado proyecto y la consecuente puesta en funcionamiento de una determinada estrategia —en este caso de control social a partir de la práctica de la beneficenciaproduce en el cuerpo social los efectos deseados, tampoco puede creerse lo contrario y trabajar teórica o empíricamente como si la misma no hubiese existido.

Según los datos que manejamos la resistencia al juego propuesto por la práctica benéfica, no parece haber sido la regla seguida por los sectores populares: ella se daba más bien en casos aislados $\mathrm{y}$, lo que es tal vez más importante, en forma desarticulada. Habría que preguntarse, además, qué tipo de resistencia podrían haber implementado los niños, que, al fin de cuentas fueron el principal objetivo del dispositivo. Evidente y no casual virtud de la estrategia benéfica fue el no ofrecer muchas posibilidades de escapatorias. Los motivos de ello están en su misma estructura interna. En principio, porque su actividad al no responder a una lógica violenta, hacía que las resistencias que pudiesen generarse en los individuos fuesen de difícil coordinación, y en segunda instancia, porque muchas de sus actividades moralizantes y disciplinadoras asumían la forma de una contraprestación material: a cambio de un bautismo una frazada, a cambio de una legalización matrimonial unos litros de leche o algunos vales de almuerzo. En un informe que el Jefe Territorial del Ejército de Salvación, coronel Palmer, eleva al Intendente Municipal en septiembre de 1917 con motivo de una recorrida que había efectuado por las calles de la ciudad de Buenos Aires, puede leerse el siguiente párrafo:

Entre las mujeres que encontramos mendigando en las calles había una, quien una semana después de haber sido vista en la calle, fue hallada en uno de los grandes hospitales de la ciudad, donde había dado a luz un niño. Pocos días después salió de la maternidad siendo visitada en su domicilio por mi esposa y otra afiliada (...) tres semanas después del nacimiento, la misma 
mujer pasaba mendigando en la calle con la criatura en los brazos (51).

También de difícil escapatoria, entonces, porque la práctica de la beneficencia permitía desarrollar constantemente múltiples miradas dentro de una ciudad en la que el anonimato comenzaba a ser teóricamente posible en la medida en que los controles directos parecían esfumarse entre la multitud.

Como señalamos, la práctica del encierro masivo de adultos era extremadamente costosa y con la puesta en marcha de políticas exclusivamente represivas sólo se podía acceder, y con un margen importante de error tante la imposibilidad de discriminar el uso de la violencia), a los sectores marginales catalogados como más peligrosos. La práctica de la beneficencia y de la caridad racionalmente organizada, cambiando la idea de exclusión por la de integración, la de represión de los considerados más peligrosos por la de control y vigilancia de los más numerosos, permite acceder a la intimidad de los hogares de la clase considerada más inestable de la sociedad. Su constante identificación y catalogación debía permitir coordinar acciones en instancias represivas posibles y necesarias, pero siempre posteriores. La sóla represión no alcanza para dar respuesta a la inmoralidad, al vicio, a la holgazanería, a la miseria, al pauperismo. La teoría de la «delincuencia natural» había puesto en claro que para la solución de los tres primeros problemas hacían falta miradas más o menos sistematizadas y presencias constantes, para tratar de anular o reducir la distancia que mantenían ciertos comportamientos de los sectores populares con las conductas que se suponía debían observar; mientras que para la solución de los últimos era indispensable un mínimo de asistencia material. El fantasma de la revuelta de los pobres ronda en las mentes de los sectores dominantes hasta que se convierte en una certeza que no puede conjugarse fácilmente con la idea de progreso indefinido. El progreso necesita de un orden social elemental y la asistencia a la población que se presume más necesitada pretende colaborar en la creación y mantenimiento de ese orden. Por eso los medios empleados en la práctica cotidiana por las sociedades de beneficencia apuntan siempre al disciplinamiento moral o laboral de los individuos. La disciplina que se puede inferir de los reglamentos de los distintos asilos, por ejemplo, apunta a

(51) Citado por Emilio ConI, Higiene social. Asistencia y previsión social. Buenos Aires cartiativo y previsor. Buenos Aires, Ipinclli, 1978, págs. 508. 
domesticar el cuerpo de los niños a través de distintos ejercicios, desde manuales a militares, y a calificar el trabajo que ese mismo cuerpo contiene, bajo un pretexto de tratamiento moral (52). Los niños que tenian la suerte de salir del asilo (53) podrían, en opinión de los ideólogos del sistema benéfico, insertarse sin dificultades en una sociedad que estaba dispuesta y ansiosa de comprarles su tiempo de trabajo y, ademas, luego podrían también reproducir el proceso en su familia.

Bueno es en este momento hacerse una pregunta clave: ¿las sociedades de beneficencia cumplen con los objetivos que se habían propuesto? Respuesta: depende de cuáles creamos que hayan sido los reales objetivos. En apariencia sus objetivos primarios pasaban por erradicar de la vida urbana la miseria, los vicios y las enfermedades, disciplinando y moralizando a los sectores populares. Pero ya en los primeros años del siglo -1910, el año del Centenario, puede ser tomado como año tipo-, la ilusión de un progreso indefinido y constante que traería aparejado consigo una sociedad sin conflictos, se habia hecho trizas y resultaba entonces difícil creer en la posibilidad de que desaparecieran los enfermos, las conventillos, los delincuentes, etc. Sin embargo, la práctica benéfica, instaurada teóricamente para ponerles fin, no sólo no desaparece sino que se incentiva, y en la segunda década del siglo $\mathrm{XX}$ se re-institucionaliza en nuevos $\mathrm{y}$ más complejos ámbitos: en los servicios de Asistencia Social de los hospitales públicos de Buenos Aires, en los Institutos Municipales de Puericultura, en los Comedores Escolares y en el Cuerpo Médico Escolar dependientes del Consejo Nacional de Educación, etc. En todos estos ámbitos se cumplen con distintos grados de efectividad las tareas de disciplina y moralización que las sociedades de beneficencia practicaron durante más de treinta años. Con el manejo médico de la asistencia social, el hospital deja de

(52) Cfr. Jacinta CASTro y otros Reglamento del Asilo de Huérfanos. Buenos Aires, El Porvenir, 1885; CASA DE Expositos. Reglamento, Buenos Aires, Peuser, 1891; Asilo de Niños Desvalidos y Escuela de ARTes y Oficios. Programa de enseñanza y reglamento interno. Buenos Aires, Coni, 1885, AsILo DE NiÑos Desvalidos, Reglamento, Córdoba, s/e, 1895.

(53) La mortalidad de niños en los asilos era extremadamente alta. Si nos remitimos a las estadísticas elaboradas por la Sociedad de Beneficencia de la Capital, notaremos que, entre los años 1852-1912, ingresaron en la Casa de Expósitos para ser asilados 40.148 niños, de los cuales murieron estando en el asilo 20.112, es decir un $50.09 \%$ del total de niños ingresados. Si tomamos los años 1880-1912, tendremos que entraron 32.725 niños (que equivale al 81,5 por ciento del total) y murieron en el asilo 16.581, es decir 50,66\% del total de niños ingresados en esos años. Elaboración propia sobre datos publicados por la Sociedad de Beneficencia de la Capital. 
ser una institución "desgraciada" para pasar a ser una herramienta adecuada para ser utilizada en el control de la población. El hecho de que esa práctica social inaugurada por las sociedades de beneficencia de sustento con el paso del tiempo a la noción de asistencialismo y se reencarne dentro de los hospitales públicos a fines de la década de 1920, prueba su éxito.

Entonces, si creemos que la práctica de la beneficencia se proponía acabar con la miseria, el pauperismo, o como quiera llamársele su fracaso fue estrepitoso. Ahora bien, si creemos que sus objetivos fueron otros, es decir, funcionar como un banco de pruebas de iniciativas prácticas, poner en movimiento una serie de instituciones a la caza de espacios territoriales dentro de la ciudad y de grupos que presten consenso; bombardear sistemáticamente el lugar de los otros con su presencia y su mirada; colaborar en la tarea de moralización de los sectores populares y en el proceso de disciplinamiento social, su triunfo fue espectacular. 